\title{
An Investigation and Analysis of e-Services in Major Subject Based Information Gateways in the World
}

\author{
Ruhua Huang1 Chang Liu2 \\ I Ruhua Huang, Center for Studies of Information Resources \\ Wuhan University, Wuhan, P.R.China, 430072 \\ ruhua2003new@yahoo.com.cn \\ 2 Chang Liu, School of Information Management, Wuhan \\ University, Wuhan, P.R.China, 430072 \\ liuchang_cl@hotmail.com
}

\begin{abstract}
Subject based information gateways (SBIGs) aim at providing professional quality-assured information resources and multifold e-services. However, since the information resources construction of SBIGs has gained lots of acclamations, much attention should be paid on e-services to attract users. Only through expedient services provided by SBIGs, can users be faithful supporters. But e-services of them have infrequently been discussed, so we looks into e-Services of ten major SBIGs in the world, with focus on their browse, search and value-added information services. The e-service in SBIGs are uneven, most of them lack in efficient services. Based on the investigation and analyses, the paper concludes with some suggestions using theories of user-centered and service-centered for improving e-services in SBIGs. The methodologies of investigation, analysis, comparison, case study and statistics are used to do this research.
\end{abstract}

\section{Introduction}

The growth of Web information continues to challenge users seeking relevant and high-quality resources on the Internet. Major search engines, such as Google and Yahoo, respond to this challenge by increasing the size of their databases and offering more powerful searching and ranking features. But they often lack the structured browsing and controlled vocabulary support. Thus, Subject Based Information Gateways (SBIGs) emerged as a response to weakness of Internet search engines. "Subject gateways are online services and sites that provide searchable and browsable catalogues of Internet based resources. Subject gateways will typically focus on a related set of academic subject areas. [1]"

Nowadays, a number of SBIGs have been developed to help users find high quality resources on the Internet. They tend to be used widely in the research, educational or cultural domains. As a result, SBIGs play a crucial role in the

Please use the following format when citing this chapter:

Huang, R., Liu, C., 2007, in IFIP Intenational Federation for Information Processing, Volume 252, Integration and Innovation Orient to E-Society Volume 2, cds. Wang, W., (Boston: Springer), pp. 209-217. 
education and research innovation, and have been conceived and carried forward as an integral part of national cyberinfrastructure in some countries.

SBIGs employ subject specialists and information professional to identify, evaluate, catalogue and organize Internet resources for inclusion in browsable and searchable Web-based gateway services to support user with qualitycontrolled resources and e-Services.

At present, the e-services of SBIGs are infrequently investigated especially for the comparison of them. This paper is an attempt to provide a detailed survey on e-Services of SBIGs and to offer some suggestions on improving them. The ten major SBIGs studied in this paper are from different countries of the world. BUBL Information Service (BUBL), intute and Biz/ed are from U.K., INFOMINE, Librarians' Index to the Internet (LII) and Gate way to 21 st Century Skills (Gateway) from U.S.A., WWW Virtual Library (VL) from Switzerland, EdNA Online: Education Network Australia (EdNA Online) from Australia, MathGuid from Germany, and Chinese National Science Digital Library (CSDL) from P. R. China.

\section{Browse Services in SBIGs}

Provide browsing of quality manually catalogued resources are essential services for SBIGs. In this part, we investigate browse services provided in the ten SBIGs.

Table 1. Browse Modes in Major SBIGs (arranged alphabetically by the SBIGs' name)

\begin{tabular}{|l|l|l|}
\hline \multicolumn{1}{|c|}{ Gateway } & Country & \multicolumn{1}{|c|}{ Browse Mode } \\
\hline Biz/ed & U.K. & By subject, status or sections \\
\hline BUBL & U.K. & $\begin{array}{l}\text { By DDC, alphabetical order, subject menus, countries } \\
\text { and resource type }\end{array}$ \\
\hline CSDL & P.R. China & By subject \\
\hline EdNA Online & Australia & By website area and all education topics \\
\hline Gateway & U.S.A. & $\begin{array}{l}\text { By subject, type, level, keywords, mediator, } \\
\text { beneficiary and price code }\end{array}$ \\
\hline INFOMINE & U.S.A. & $\begin{array}{l}\text { By subjects, keywords, authors, titles and resource } \\
\text { types }\end{array}$ \\
\hline intute & U.K. & By subject headings \\
\hline LII & U.S.A. & By subject \\
\hline MathGuide & Germany & By subject, source type and journal list \\
\hline VL & Switzerland & By subject \\
\hline
\end{tabular}

Table 1 shows all the ten described SBIGs provide browsing services, nine of them support browse by subject, typically based on classification schemes. Some even add other browsing mode according to their characteristics. Gateway provides seven browse choices and it is the best integrated one among the ten.

\section{Search Services in SBIGs}

Searching presents modes of SBIGs' information retrieval system. To carry out a search combining different search fields help focusing search on specific kind of 
information. Meanwhile, a search query by using search operators can make search results more relevant and precise. The focus of this part was on the investigation of search services in the ten SBIGs. It consists of three main parts: search modes, search fields and search operators.

\subsection{Survey on Search Modes in Major SBIGs}

Table 2. Search Modes in Major SBIGs

\begin{tabular}{|l|c|c|l|}
\hline \multirow{2}{*}{ Gateway } & \multicolumn{3}{|c|}{ Search Mode } \\
\cline { 2 - 4 } & Simple & Advanced & \multicolumn{1}{|c|}{ Others } \\
\hline Biz/ed & $\sqrt{ }$ & $\sqrt{ }$ & \\
\hline BUBL & $\sqrt{ }$ & $\sqrt{ }$ & Combined search \\
\hline CSDL & $\sqrt{ }$ & $\sqrt{ }$ & \\
\hline EdNA Online & $\sqrt{ }$ & $\sqrt{ }$ & $\begin{array}{l}\text { Distribute search, sector search, Browse } \\
\text { category search }\end{array}$ \\
\hline Gateway & \multicolumn{2}{|c|}{ Faceted search } \\
\hline INFOMINE & $\sqrt{ }$ & $\sqrt{ }$ & \\
\hline intute & $\sqrt{ }$ & $\sqrt{ }$ & \\
\hline LII & $\sqrt{ }$ & $\sqrt{ }$ & Facet navigation \\
\hline MathGuide & $\sqrt{ }$ & $\sqrt{ }$ & \\
\hline VL & $\sqrt{ }$ & $\sqrt{ }$ & \\
\hline
\end{tabular}

It can be seen from table 2 that the studied SBIGs use different modes to provide search services, including simple search, advanced search, combined search, distribute search, sector search and faceted search. Generally speaking, the most common search method is the simple search and advanced search mode options. Simple search in these SBIGs only supports search in some limited fields, while advanced search combines a wide variety of search fields and several displayed choices. The advanced search in every SBIG has its special functions, taking CSDL as an example, it provides the function of conserve searching data and offers them to user when they log in next time.

Some characteristics with regard to searching should be pointed out. Several of them add combined search, distribute search, sector search as a supplementary. Faceted search is also used in such well-developed SBIGs like LII, Gate way to 21st Century Skills and EdNA Online. Faceted search, which combines the processes of searching for specific words and phrases with browsing resources based on subject facets, is an excellent way and also a trend in searching area.

\subsection{Survey on Search Fields in Major SBIGs}

Table 3. Search Fields in Major SBIGs

\begin{tabular}{|l|l|}
\hline Gateway & \multicolumn{1}{|c|}{ Search Fields } \\
\hline Biz/ed & keywords \\
\hline BUBL & title, subject terms, author, description, resource type \\
\hline
\end{tabular}




\begin{tabular}{|c|c|}
\hline CSDL & $\begin{array}{l}\text { title, classification, subsidiary title, editor, author, publisher, URL, } \\
\text { publish year, type of institution and resources, language, record type }\end{array}$ \\
\hline $\begin{array}{l}\text { EdNA } \\
\text { Online }\end{array}$ & $\begin{array}{l}\text { title, subject, audience, creator, date, description, EdNA category, } \\
\text { identifier, location, publisher, search area, search site, thesaurus selecting, } \\
\text { repository selecting }\end{array}$ \\
\hline Gateway & title, keywords, full text, description \\
\hline INFOMINE & $\begin{array}{l}\text { title, subject, author, keyword, description, full text ,subject } \\
\text { categories, record origin(expert created or robot), resource access, } \\
\text { resource types }\end{array}$ \\
\hline intute & title, description, keywords, subject groups, resource type \\
\hline LII & title, URL, description \\
\hline MathGuide & $\begin{array}{l}\text { title, keywords, names, MSC, codes, language, country, source type, } \\
\text { dates, last update, text, }\end{array}$ \\
\hline $\mathrm{VL}$ & $\begin{array}{l}\text { title, subject, author, keyword, description, words forms(all or exact), } \\
\text { use synonyms (yes/no), document types, URL matches }\end{array}$ \\
\hline
\end{tabular}

Table 3 shows that the search fields which are frequently used in SBIGs are: title, subject, author, keyword, description and document types. The number of search fields in each SBIG is very variable, from 5 of LII to 14 of EdNA Online. Each of them designs a variety of useful fields. VL uses match, search for, words forms and synonyms fields to help users express search terms precisely and conveniently, so does Biz/ed. INFOMINE set record origin fields to identify the manually quality-controlled resources or robot-generated databases, as well as set resource access fields to separate the free access resources from the paid ones. EdNA Online allows search result to be restricted from all sites or Australian sites via search site field, from all types of EdNA resources or any sector of them via search area field, from the internal EdNA resources or some well-recognized repository outside via the repository selecting fields. Comparatively speaking, the SBIGs which used faceted search like LII and Gate way to 21st Century Skills have few fields but higher search efficiency and convenience than others.

\subsection{Survey on Search operators in Major SBIGs}

Table 4 shows a statistic as follows. In SBIGs described above, $100 \%$ of them support Boolean logic, $70 \%$ support truncation, half provide phrase operator. However, several SBIGs use other search operators like parentheses, fuzzy, proximity and spell-check. For example, INFOMINE and VL support parentheses, but LII provide the greatest number of search operators. Additionally, some of them integrated search operators into the interface as a search box, which means that SBIGs become more and more intellectual and humane.

Table 4. Search Operators in Major SBIGs

\begin{tabular}{|l|l|l|l|l|}
\hline \multirow{2}{*}{ Gateway } & \multicolumn{4}{|c|}{ Search Operators } \\
\cline { 2 - 5 } & Boolean Logic & Truncation & Phrase & Others \\
\hline Biz/ed & AND,OR & & & \\
\hline BUBL & AND,OR,NOT & $*, ?$ & & \\
\hline CSDL & AND, NOT(-) & & " & \\
\hline EdNA Online & AND,OR,NOT & & & \\
\hline
\end{tabular}




\begin{tabular}{|c|c|c|c|c|}
\hline Gateway & AND,OR,NOT & * & " " & Spell-check \\
\hline INFOMINE & AND,OR,NOT & $*$ & " ", | & $\begin{array}{l}\text { Proximity(Near"n } \\
\text { ") }\end{array}$ \\
\hline intute & AND,OR,NOT & * & " " & \\
\hline LII & $\begin{array}{l}\mathrm{AND}(+), \mathrm{OR}, \mathrm{NO} \\
\mathrm{T}(-)\end{array}$ & * & $“ "$ & $\begin{array}{l}\text { Spell-check, } \\
\text { stemming }\end{array}$ \\
\hline MathGuide & AND,OR,NOT & $?$ & & \\
\hline VL & $\begin{array}{l}\operatorname{AND}(\&), \operatorname{OR}(0) \\
\operatorname{NOT}(\sim)\end{array}$ & * & & Fuzzy \\
\hline Total & $100 \%$ & $70 \%$ & $50 \%$ & $40 \%$ \\
\hline
\end{tabular}

\section{Survey on Value-added Information Services Provided by SBIGs}

Table 5. Value-added Information Services in Major SBIGs

\begin{tabular}{|c|c|c|c|c|c|c|}
\hline \multirow[b]{2}{*}{ Gateway } & \multicolumn{6}{|c|}{ Information Services } \\
\hline & $\begin{array}{l}\text { Virtual } \\
\text { referenc } \\
\text { e service }\end{array}$ & $\begin{array}{l}\text { Newslet } \\
\text { ter }\end{array}$ & $\begin{array}{l}\text { Archi } \\
\text {-ves } \\
\text { offer }\end{array}$ & $\begin{array}{l}\text { Informa } \\
\text { tion } \\
\text { push }\end{array}$ & $\begin{array}{l}\text { Persona } \\
\text {-lization } \\
\text { service }\end{array}$ & Others \\
\hline Biz/ed & & $\sqrt{ }$ & $\sqrt{ }$ & & & \\
\hline BUBL & $\sqrt{ }$ & & $\sqrt{ }$ & & & \\
\hline CSDL & $\sqrt{ }$ & $\sqrt{ }$ & & $\sqrt{ }$ & $\sqrt{ }$ & $\begin{array}{l}\text { Subject' } \\
\text { s forum }\end{array}$ \\
\hline $\begin{array}{l}\text { EdNA } \\
\text { Online }\end{array}$ & $\sqrt{ }$ & $\sqrt{ }$ & $\sqrt{ }$ & $\sqrt{ }$ & $\sqrt{ }$ & $\begin{array}{l}\text { Group } \\
\text { space }\end{array}$ \\
\hline Gateway & $\sqrt{ }$ & $\sqrt{ }$ & & & $\sqrt{ }$ & \\
\hline INFOMINE & $\sqrt{ }$ & & & $\sqrt{ }$ & & \\
\hline intute & $\sqrt{ }$ & $\sqrt{ }$ & & & $\sqrt{ }$ & $\begin{array}{l}\text { Job } \\
\text { search }\end{array}$ \\
\hline LII & & $\sqrt{ }$ & & $\sqrt{ }$ & & \\
\hline MathGuide & $\sqrt{ }$ & & & & & \\
\hline $\mathrm{VL}$ & & $\sqrt{ }$ & $\sqrt{ }$ & & & \\
\hline Total & $70 \%$ & $70 \%$ & $40 \%$ & $40 \%$ & $40 \%$ & $30 \%$ \\
\hline
\end{tabular}

Table 5 shows that the value-added information services provided by the ten SBIGs focus on several types listed above. Virtual reference services(VRS)and newsletter are the most frequently provided services in SBIGs, the follow ones offered is information push, archives offer and personalization services.

The first kind of virtual reference service mode is to reveal general reference resources. For instance, BUBL exploits a directory of UK organizations and institutions. MathGuide collects journal information about math. INFOMINE even integrate Google, Altavista, All the Web, Hotbot, Teoma and Wisenut to be a meta search engine and recommend Internet search engines \& finding tools to users. Only Gateway provides "ask and answer questions" service. Newsletter service often selects news in the related subject areas, users can subscribe by email or RSS or just read online to get this service from some SBIGs like LII. 
Information push is more and more prevail, both users and the websites can get benefit from it. In SBIGs, the email notification service will keep users informed of the latest information resources they customized. Establishing archives is a method to preserve precious resources. BUBL provide "E-LIS", an open archive for Library and Information Science. VL also set out the archives of papers, presentations, audio materials and history about it. The most noteworthy example is that the personalized service of intute is classified to certain groups of users particularly and pertinently.

Virtual training should be a very useful service to improve users' information literacy, but only intute supports it. Other special kinds of information services are job search by intute, subject's forum by CSDL, group space by EdNA Online.

\section{Suggestions for Improving e-Services in SBIGs}

Although the studied SBIGs are appreciated by their user communities, they face challenges from automated search engines. Powerful search engines including Google have used advanced techniques to improve the quality of search results. In order to advance and perfect the quality of e-Services of SBIGs, some areas for future developments are given below.

\subsection{Reforming Browsing and Searching Interfaces}

While the SBIGs have developed many kinds of searching and browsing ways, some future work might include further enhancements of the searching and browsing interfaces. Surveying the SBIGs, we find that the concision, practicability and amicability have great influence on users' willing of using SBIG. Analysis of Renardus usage logs also suggests that "systematic browsing of large information systems with the help of classification hierarchies seems to be widely accepted by users, especially when there is graphical support" [2].

LII doesn't provide so many search modes as other SBIGs, but it is the most wieldiest one. In LII, users do not have to spend time on scanning the dazzling interfaces and deciding which one they should $\log$ in or $\log$ out. The whole interface of the gateway is quite clear with an obvious navigation system, which allows user switching between searching and browsing. It is also a secret of LII's success, despite of the specialization.

\subsection{Progressing Integration of Resources and Services}

Integration should mean enhancing and maximizing the value of existing infrastructure services and combining their service delivery with new mechanisms which exploit new technologies [3]. Integrated access to digital resources depend on the uniform descriptions of information resources. Nowadays, the development of metadata and new technical architectures make it possible. The integration of information resources aims at better e-services. Service-centered must be the principle in the progress of SBIGs.

Except such basic services as browse and search options, SBIGs should provide additional, valued-added services, such as producing thesauri, delivering 
training, setting up personalized alerts for new online resources and giving advice on users' searching, and integrate all these services so that end users can get one-site services. Intute is a typical illustration. In July 2006, it re-launched as a single service through integrating eight good U.K. SBIGs (Altis, Artifact, BIOME, EEVL, GEsource, Humbul, PSIgate and SOSIG) to centralize the forces and actualize the supplement among them. Intute provides united services and has more achievements in the world than before.

In order to enhance information services in SBIGs, the UK's Joint Information Systems Committee (JISC) funded a two-year project ending August 2003- - The Subject Portals Project. The portal services include a single sign-on access management system; a cross-searching tool; a user profiling system; and other "additional services" [4]. This system is a successful model, which has integrated basic and value-added services.

\subsection{Strengthening Investigation and Feedback of User's Requirement}

User-centered has been always the ideal of all services including e-services in SBIGs. A SBIG must assess accurately the needs of the prime target audience and meet the needs of its user community. At present, there are three kinds of communication between providers and users in SBIGs: virtual reference, information push and users' feedback. Although SBIGs have diversified traits, the ultimate purpose is to improve their services. The communications help both users and providers.

It is a piece of good news that most SBIGs discussed above emphasize information push services. Nevertheless, the implement of VRS is not so optimistic. Real-time reference service is not provided by these SBIGs, what they offer are just related reference resources. Theories and practices of multiple models of virtual reference service should be applied to further development of SBIGs. The users' feedback is helpful for providers to improve services. The current users' feedback system is not consummate enough for users to estimate effectively. Enhancing and perfecting the construction of the SBIGs' communication system is still a handicap for the developers to conquer.

Besides direct communication between users and providers, some deep investigation and analysis should be done among users. In 2001, an evaluation study was done with attempts to evaluate ADAM in terms of real searching behavior obtained by users' feedback and provides some detailed information on who these digital users are, how often they use the service, etc [5].

\subsection{Paying Attention to Promotion of e-Service}

In order to become a popular service and gain acceptance as a valid information retrieval tool amongst its target audience, a SBIG should use a number of methods and a variety of media to promote itself and its services like other successful commerce case. News about a particularly important milestone of SBIG, or a new service or interface released should be posted to the target audience in a number of newsgroups and e-mail discussion groups by information push services, it is the basic way which the SBIGs usually do. Some other methods are still needed, for example, publishing advertisements on various media like TV, radio, high-click rate websites, even distributing small 
gifts with some information of SBIGs on including calendars, pens, cups and unusually-designed leaflets.

Some SBIGs has done very well in this way. Ongoing promotion, by a variety of methods, has been recognized as a means of raising awareness of the development of the Edinburgh Engineering Virtual (EEVL) amongst its target audience. As a result, usage of EEVL has rapidly increased in recent months, with current figures indicating a daily average of over 9,000 page views [6].

\section{Conclusion}

Despite the variety of search engines in use and the proliferation of search tools, there is still a need for human intervention to guide the search process by adding a subject gateway [7]. SBIGs should save users' time, connect them to qualitycontrolled resources and services to support their learning, teaching and research. The key issues which need to be addressed for the future development of information services in SBIGs are: continued quality of services, reinforced the value of existing service provision methods, sustainability of services and service integration [8].

In order to provide a better and more sustainable subject orientated service to a wider audience, more efforts should be put on the specialization, efficiency and accuracy of e-Services in SBIGs. Increased collaboration between SBIGs would be a good solution, for example, exchange records, cross-browsing, crosssearching, mirroring remote service, cooperative digital reference services, shared development of technological solutions and online tutorials, etc. This includes cooperation between SBIGs in a subject area and cooperation between SBIGs in different countries as well as international collaboration.

\section{Acknowledgment}

This research was supported by the National Planning Office of Philosophy and Social Science, P.R. China (Project No. 06\&ZD031).

\section{References}

1. What is a subject gateway? (May 16, 2007); http://www.desire.org/html/Subjectgate ways/subjectgateways.html.

2. M. Day, T. Koch, H. Neuroth, Searching and browsing multiple subject gateways in the Renardus Service, Proceedings of the RC33 Sixth International Conference on Social Science Methodology. Amsterdam, Stuttgart(2004).

3. Debbie Campbell, "Australian subject gateway: political and strategic issues", Online Information Review. Vol. 24, 73-77 (2000).

4. Ruth Martin, "The subject portals project: Enhancing the delivery of subject-based information to the UK further and higher education community", The Serials Librarian. Vol. 45, 39-48 (2004).

5. Maria Monopoli, David Nicholas, A User Evaluation of Subject Based Information Gateways: Case Study ADAM, Aslib Proceedings. 53(1), 39-52 (2001). 
6. Roddy MacLeod, "Promoting a subject gateway: a case study from EEVL" (Edinburgh Engineering Virtual Library), Online Information Review. Vol. 24, 63(2000).

7. Krishnamurthy, M,'Designing a gateway interface: conceptual framework for library and information science", Information Studies. Vol.11, 195204(2005).

8. Nejdl Wolfgang, Innovative information and knowledge infrastructures How do I find what I need?, Advances in information systems. Proceedings lecture notes in computer science. 4243, 34-37(2006). 